\title{
Comparative Susceptibility Study Against Pathogens Using Fermented Cranberry Juice and Antibiotics
}

\author{
loanna Mantzourani ${ }^{1 *}$, Christos A. Bontsidis ${ }^{1}$, Stavros Plessas ${ }^{1}$, \\ Athanasios Alexopoulos ${ }^{1}$, Eirini Theodoridou' ${ }^{1}$, Christina Tsigalou ${ }^{2}$, Chrysa Voidarou $^{3}$, \\ George Douganiotis ${ }^{4}$, Stavros L. Kazakos ${ }^{1}$, Elisavet Stavropoulou ${ }^{5}$ and \\ Eugenia Bezirtzoglou ${ }^{1}$

\begin{abstract}
Laboratory of Microbiology, Biotechnology and Hygiene, Faculty of Agriculture Development, Democritus University of Thrace, Orestiada, Greece, ${ }^{2}$ Department of Agriculture, Faculty of Agriculture, Food Science, Nutrition, University of loannina, Ioannina, Greece, ${ }^{3}$ Laboratory of Microbiology, Medical School, Democritus University of Thrace, Alexandroupolis, Greece, ${ }^{4}$ Theageneio Cancer Hospital, 3rd Department of Clinical Oncology, Thessaloniki, Greece,
\end{abstract} \\ ${ }^{5}$ Service de Medicine Interne, Centre Hospitalier Universitaire Vaudois, Lausanne, Switzerland
}

OPEN ACCESS

Edited by:

Fatih Ozogul,

Çukurova University, Turkey

Reviewed by:

Ömer Şimşek

Pamukkale University, Turkey

Pinar Yerlikaya,

Akdeniz University, Turkey

Cengiz Gokbulut,

Balıkesir University, Turkey

*Correspondence:

Ioanna Mantzourani imantzou@agro.duth.gr

Specialty section:

This article was submitted to

Food Microbiology,

a section of the journal

Frontiers in Microbiology

Received: 12 March 2019 Accepted: 23 May 2019

Published: 07 June 2019

Citation:

Mantzourani I, Bontsidis CA,

Plessas S, Alexopoulos A,

Theodoridou E, Tsigalou C,

Voidarou C, Douganiotis G, Kazakos SL, Stavropoulou E and Bezirtzoglou E (2019) Comparative

Susceptibility Study Against

Pathogens Using Fermented

Cranberry Juice and Antibiotics.

Front. Microbiol. 10:1294.

doi: 10.3389/fmicb.2019.01294
In the present study, unfermented and fermented cranberry juice in combination with the Antibiotics vancomycin and tigecycline were tested for their antimicrobial activity. Cranberry juice was fermented with a recently isolated potentially probiotic Lactobacillus paracasei K5. The tested strains selected for this purpose were Enterococcus faecalis, E. faecium, Enterobacter cloacae and Staphylococcus aureus. The methods followed were the determination of zones inhibition, Minimum Inhibitory Concentration (MIC) and Fractional Inhibitory Concentration Index (FICl). Tigecycline together with fermented juice exhibited larger Zones of Inhibition (ZOI) in strains of $E$. faecium (65 $\pm 4.8 \mathrm{~mm}$ ) compared to the respective ZOI with tigecycline and unfermented juice (no zone). The same outcome was also obtained with E. cloacae. Vancomycin together with fermented juice exhibited larger $\mathrm{ZOI}$ in strains of $E$. faecium $(28 \pm 2.2 \mathrm{~mm}$ ) compared to the respective $\mathrm{ZOI}$ with vancomycin and unfermented juice $(24 \pm 2.3 \mathrm{~mm})$. The lowest MIC values were recorded when tigecycline was combined with fermented cranberry juice against $S$. aureus strains, followed by the same combination of juice and antibiotic against $E$. cloacae strains. $\mathrm{FICl}$ revealed synergistic effects between fermented juice and tigecycline against a strain of $E$. faecium (A2020) and a strain of $E$. faecalis (A1940). Such effects were also observed in the case of fermented juice in combination with vancomycin against a strain of $S$. aureus (S18), as well as between fermented juice and tigecycline against E. cloacae (E1005 and E1007) strains. The results indicate that the antibacterial activity of juice fermented with the potentially probiotic $L$. paracasei $K 5$ may be due to synergistic effects between some end fermentation products and the antibiotic agents examined.

Keywords: antibiotics, pathogens, probiotic, cranberry juice, fermentation

\section{INTRODUCTION}

Cranberries are perennial plants, with characteristic reddish color, which belong to section Cyanococcus, genus Vaccinum. The greater family is Ericaceae, a family of edible fruits which also includes blueberries and gooseberries. These fruits are rich in phenolics (flavonoids, flavonols, catehins, and anthocyanins), organic acids (citric, malic, benzoic, and ferulic), and, in the case 
of cranberries, also proanthocyanins - a special group of condensed tannins. Cranberries are cultivated in Central and Northern Europe, and also Canada and Chile (Vattem et al., 2005). They first came into the spotlight because of their biological properties and health benefits to consumers.

Lactic acid bacteria (LAB) belong to a wide bacteria family whose fermented activity ends with lactic acid. They include species such as Lactobacillus. plantarum, L. sakei, L. casei, L. paracasei, L. fermentum, Leuconostoc mesenteroides, Weissela confuse, W. cibaria, Pediococcus pentosaceus (Todorov et al., 2008). These strains are used in several traditional food fermentation methods for liquid state fermentation (LSF) with plant- based substrates. The main reason for their use is the belief that they induce health benefits, including the production of bioactive compounds, as well as possess antimicrobial, antiinflammatory, and antioxidant (Liu et al., 2011; Liao et al., 2013; Torino et al., 2013; Limon et al., 2015), and antiobesity (Lee et al., 2013) properties (Muhammed et al., 2018).

The microenvironment within fruit juices favors LAB fermentation, due to availability of minerals and vitamins, and an acidic pH (2,4-3,5) (Kim et al., 2014; Swain et al., 2014). During lactic fermentation of fruit juices, flavonoids are released, resulting in high antioxidative activity. With the application of suitable strains, a large variety of enzymes, such as glucosidases, amylases, celluloses, xylanases, esterases, invertases and lipases, alter the structure of phytochemical compounds present in fruit juices. LAB contribute to the degradation of high molecular weight phenolic compounds (Othman et al., 2009; Hur et al., 2014). Supplementary factors, contributing to microbial inhibition and antioxidative activity of fermentation products by $\mathrm{LAB}$ are: low $\mathrm{pH}$, hydrogen peroxide, oxygen, temperature, time and extraction and bacteriocins (Kantachote et al., 2008). In our study, the probiotic strain Lactocacilus paracasei K5, previously characterized in our laboratory (Plessas et al., 2017), was used for the fermentation of cranberry juice.

Lactobacillus paracasei exists as part of the normal flora of the human gastrointestinal tract. Naturally fermented vegetables, milk, and meat may also contain strains of L. paracasei (Swain et al., 2014). The strain used in the present study was a wild one isolated in our laboratory that exhibited antioxidant, probiotic, and antiproliferative properties (Chondrou et al., 2018). For this reason, it was selected in order to examine the properties of a fermented cranberry juice compared to an unfermented one.

Natural products, like cinnamon extracts, essential oils, and their compounds may inhibit bacteria by various methods, such as damaging the cell membrane, altering the lipid profile, inhibiting ATPases, cell division, membrane porins, motility, and biofilm formation (Vasconcelos et al., 2018). Particularly for cranberry, a study has shown to prevent urinary tract infections by interfering with bacterial adhesion in the urinary tract (Howell et al., 1998). Uropathogenic Escherichia coli strains are not able to adhere to bladder cell receptors (Howell et al., 2010) and thus, cell growth is inhibited and infection is prevented. It has been speculated that the observed reduction in adhesion may be due to changes in bacterial morphology (Liu et al., 2006) and/or genetically based decreases in P-fimbrial expression (Ahuja et al., 1998; Liu et al., 2006).
In another study, antiadherence properties were demonstrated when cranberry extracts were applied against pathogens. These effects have been associated with cranberry juice inhibiting E. coli adherence to uroepithelium and its subsequent multiplication (Blumberg et al., 2013; Jensen et al., 2017; Kim et al., 2019).

Antibiotic agents are chemical substances derived from bacteria or fungi that inhibit the growth of other strains. The basic mode of inhibition includes blocking basic cellular procedures, like cell wall synthesis, transcription, translation, energy production, etc. In the present study, two broad-spectrum antibiotic substances, vancomycin and tigecycline, were tested for their activity against pathogenic strains. Vancomycin is a glycopeptide antibiotic which acts by inhibiting cell wall synthesis and is used for the treatment of Gram-positive bacteria. Tigecycline is a tetracycline antibiotic which acts by inhibiting protein synthesis and is used against both Gram- negative and Gram-positive bacteria. In our study, vancomycin was used against Staphylococcus aureus strains and tigecycline was selected mostly against Enterococcus spp. and Enterobacter spp. based on the results of a previous study in our laboratory (Mantzourani et al., 2015).

Enterococcus spp. are commonly responsible for severe infections of the urinary tract, septicemia and meningitis. Especially E. faecium has been a leading cause of multidrug resistant enterococcal infections. E. spp. are commonly responsible for infections of the urinary and respiratory tracts (Fisher and Phillips, 2009). S. aureus can cause pneumonia, meningitis, bacteremia and sepsis. It should be noted that $S$. aureus strains are part of the normal skin flora and are normal inhabitants of the lower reproductive tract of women.

In the present study, the antimicrobial activity of cranberry juice, both unfermented and fermented with L. paracasei K5 (Plessas et al., 2017), was tested against several pathogens, like S. aureus, E. faecium and E. faecalis and E. cloacae. The results were compared with the action of two antibiotic agents, Vancomycin and Tigecycline against the same pathogens. The Fractional Inhibitory Concentration Index (FICI) was calculated in each case in order to examine synergism or antagonism of their bioactive components.

The goal of the study was to investigate whether or not fermented cranberry juice and commercial antibiotics can be used in combination as an alternative treatment to multi-drug resistant bacterial infections, by pinpointing the decrease of the minimum inhibitory concentration of these severe pathogens with the simultaneous consumption of cranberry juice.

\section{MATERIALS AND METHODS}

\section{Cranberry Fruit Preparation for Fermentation}

Ten kilograms of fresh cranberry fruits were obtained directly from a farm in Marasia, north-eastern Greece. The fresh fruits were carefully selected, washed, the kernel was removed, and the fruits processed into juice by blending for $10 \mathrm{~min}$ in a common household blender. The final product was added into deionized water (1:2 proportion) and the mixture was submitted 
to blanching at $90^{\circ} \mathrm{C}$ constant temperature for $2 \mathrm{~min}$. The remaining juice was extracted by cloth filtration and pasteurized at $80^{\circ} \mathrm{C}$ for $5 \mathrm{~min}$. The initial value of $\mathrm{pH}$ was adjusted to 3.5 through the addition of $\mathrm{NaOH} 0.1 \mathrm{M}$. A dilution of L. paracasei $K 5$ with turbidity of $0.5 \mathrm{McF}$ arland scale was added in $100 \mathrm{~mL}$ of fermentation substrates. The final concentration of the probiotic strain was $2 \% \mathrm{w} / \mathrm{v}$, viability approximately $10^{8} \mathrm{CFU} / \mathrm{mL}$. The unfermented samples were incubated for $24 \mathrm{~h}$ at $30^{\circ} \mathrm{C}$ for fermentation. The fermentations were carried out in triplicate. The fermented and the unfermented juice samples were tested for their antimicrobial activity against pathogens: S. aureus, E. faecium, E. Faecalis, and E. cloacae.

\section{Microbiological Analysis}

Fermented and unfermented juice samples were screened for their antibacterial activity, according to the agar well diffusion method proposed by the CLSI (former NCCLS) against the following nosocomial pathogens: S. aureus, E. faecium, E. faecalis and E. cloacae.

All the above bacteria were cultivated in Trypticase Soy Broth (TSB) at $37^{\circ} \mathrm{C}$ for $18 \mathrm{~h}$ and purified on blood agar plates (Merck Co., United States) supplemented with 5\% sterile defibrinated sheep's blood.

The antibiograms were conducted on Muller Hinton Agar (M173-500G HIMEDIA, India) with the disk diffusion method. Accordingly, a $10 \mu \mathrm{L}$ aliquot of each juice sample was added on sterile disks and cultures were incubated at $37^{\circ} \mathrm{C}$ for $18 \mathrm{~h}$. Antibacterial activity was assessed by measuring (with a caliper) the diameter of the inhibition zones surrounding the disks. The same process was followed for the evaluation of the antimicrobial activity of two antibiotics against pathogens. The antibiotics examined were Vancomycin (30 $\mu \mathrm{g} /$ disk HIMEDIA) and Tigecycline (15 $\mu \mathrm{g} /$ disk HIMEDIA). The inoculated plates were allowed to stand at room temperature for $15 \mathrm{~min}$ prior to dispensing the paper disks and the plates incubated at $37^{\circ} \mathrm{C}$ for $24 \mathrm{~h}$. The diameters of the clear zones around each disk were measured after incubation.

During the microdilution method, antimicrobial drugs were tested in the range of $0.5-512 \mu \mathrm{g} / \mathrm{mL}$ for vancomycin, in the range of $0.002-2 \mu \mathrm{g} / \mathrm{mL}$ for tigecycline and the fermented and the unfermented juice in the range of $1-1024 \mu \mathrm{g} / \mathrm{mL}$. The above concentrations were chosen based on analogous published reports (Wojnicz et al., 2016), to be comparable with the concentration of antibiotics and to be at least four times above/ below the MIC for the estimation of FIC values. A control test was performed without any antimicrobial agent. MIC was defined as the lowest concentration of antimicrobial agent that inhibited the visible growth of test organism. Each experiment was conducted in triplicate.

\section{Determination of FIC and FIC Index (FICI)}

The combined effect of the two antibiotics and the fermented unfermented juice (FIC) was evaluated by the microdilution chequerboard method with some modifications (Fratini et al., 2017). In the first of a series of six test tubes each containing $20 \mathrm{~mL}$ Mueller-Hinton broth, an amount of $163.84 \mu \mathrm{L}$ fermented or unfermented juice was added (equal to a concentration of
$8192 \mu \mathrm{g} / \mathrm{mL}$ or eight times the estimated MIC). Then, $10 \mathrm{~mL}$ from the first tube was serially diluted up to the sixth tube. The final $10 \mathrm{~mL}$ were discarded. Test tubes with antibiotics (tigecycline and vancomycin) were prepared accordingly. $160 \mu \mathrm{L}$ from each tube with cranberry juice were transferred to the first, second, third, etc., column of a 96 micro-well plate. An equal amount $(160 \mu \mathrm{L})$ from the test tubes containing the antibiotics were added to the first, second, third, etc., row of the same micro-plate. In this manner the top-left well was contained a combination of four times the MIC of juice and four times the MIC of antibiotic followed by a series of dilutions of the above in order to obtain the FIC final concentrations (4 MIC0, $2 \mathrm{MIC0}, 1 \mathrm{MIC}$, MIC0/2, MIC0/4, and MIC0/8). Finally, $10 \mu \mathrm{L}$ of bacterial suspension standardized at $0.5 \mathrm{McF}$ arland standard turbidity units were added in each well, except the negative control, in which $10 \mu \mathrm{L}$ of sterile BHI (Brain Heart Infusion) broth was added. Microplates were incubated at $37^{\circ} \mathrm{C}$ for $24 \mathrm{~h}$. FIC determinations were performed in triplicate. For each experiment, FICI values were calculated using the following formula:

$$
\text { FICI }=\text { FICjuice }+ \text { FICantibiotic }
$$

where FICjuice $=$ MICjuice in combination/MICjuice alone and FICantibiotic = MICantibiotic in combination/MICantibiotic alone.

According to EUCAST (2000) a Synergistic effect is observed when FICI value $\leq 0.5$; an Additive effect when $0.5<$ FICI value $\leq 1$; an Indifferent effect when $1<$ FICI value $<2$ and an Antagonistic effect when FICI value $\geq 2$.

\section{Statistical Analysis}

Inhibition zones ( $\mathrm{mm}$ ) of fermented and unfermented cranberry juice were compared for any difference of the mean by using the Student $t$-test at a significance level of 0.05 . Inhibition zones among the two antibiotics with fermented and unfermented cranberry juice were compared by using the ANOVA procedure with Tukey's HSD post hoc comparison. All analyses were performed with IBM SPSS Statistics for Windows, Version 20.0 (Armonk, NY, United States: IBM Corp).

\section{RESULTS}

\section{Antimicrobial Activity With Zones Inhibition Method}

The zones of inhibition (ZOI) were measured following the application of cranberry juice, both unfermented and fermented with L. paracasei K5. The concentration of unfermented cranberry juice used was $1000 \mathrm{mg} / \mathrm{mL}$ while that of fermented juice was the same after $24 \mathrm{~h}$ of fermentation with the addition of L. paracasei $\mathrm{K} 52 \% \mathrm{w} / \mathrm{v}$ (turbidity $10^{8} \mathrm{CFU} / \mathrm{mL}$ ). The results are summarized in Table $\mathbf{1}$.

In the case of E. faecium, the A2020 and A1707 strains exhibited the largest ZOI with fermented and the unfermented juice $(10.75 \pm 1.2,10.45 \pm 1.1 \mathrm{~mm}$ and $10.70 \pm 1.2$, $10.55 \pm 1.4 \mathrm{~mm}$, respectively). E. faecalis strains A1951 and A1966 showed the greatest ZOI ranging from $17.75 \pm 2.1$ 
TABLE 1 | Inhibition zones for $10 \mu \mathrm{L}$ unfermented and $10 \mu \mathrm{L}$ fermented cranberry juice (1000 mg/mL+2\% L. paracasei) alone against Enterococcus faecium, E. faecalis, Enterobacter cloacae and S. aureus.

\begin{tabular}{|c|c|c|}
\hline Isolate & Unfermented cranberry juice ZOI & Fermented cranberry juice ZOI \\
\hline & $(\mathrm{mm})$ & $(\mathrm{mm})$ \\
\hline \multicolumn{3}{|c|}{ Enterococcus faecium } \\
\hline A 1337 & No zone & No zone \\
\hline A 1658 & No zone & No zone \\
\hline A 1668 & No zone ${ }^{a}$ & $8.25 \pm 0.5^{b}$ \\
\hline A 2020 & $10.45 \pm 1.1^{a}$ & $10.75 \pm 1.2^{\mathrm{a}}$ \\
\hline A 1709 & $10.55 \pm 1.4^{\mathrm{a}}$ & $10.70 \pm 1.2^{\mathrm{a}}$ \\
\hline \multicolumn{3}{|c|}{ Enterococcus. faecalis } \\
\hline A 1931 & No zone & No zone \\
\hline A 1957 & No zone & No zone \\
\hline A 1940 & No zone & No zone \\
\hline A 1951 & $17 \pm 1.6^{a}$ & $17.75 \pm 2.1^{\mathrm{a}}$ \\
\hline A 1966 & $15 \pm 1.8^{a}$ & $15.45 \pm 1.8^{\mathrm{a}}$ \\
\hline \multicolumn{3}{|c|}{ Enterobacter cloacae } \\
\hline E 1000 & No zone & No zone \\
\hline E 1002 & No zone & No zone \\
\hline E 1004 & No zone & No zone \\
\hline E 1005 & $13 \pm 1.1^{\mathrm{a}}$ & $14 \pm 1.8^{a}$ \\
\hline E 1007 & $11 \pm 0.5^{a}$ & $13 \pm 1.5^{\mathrm{b}}$ \\
\hline \multicolumn{3}{|c|}{ S. aureus } \\
\hline S 1530 & No zone & No zone \\
\hline S 15 & No zone & No zone \\
\hline S 12 & No zone & No zone \\
\hline S 18 & No zone ${ }^{a}$ & $8.2 \pm 0.4^{b}$ \\
\hline S 16 & No zone ${ }^{a}$ & $9.5 \pm 1.0^{b}$ \\
\hline
\end{tabular}

Different superscript letters indicate a statistically significant difference between the two means (Student's t-test).

to $17 \pm 1.6 \mathrm{~mm}$ and $15 \pm 1.8$ to $15.45 \pm 1.8 \mathrm{~mm}$ with fermented and the unfermented juice samples, respectively. $S$. aureus strains displayed the lowest values of inhibition zones, since their diameter reached $8.2 \pm 0.4$ and $9.5 \pm 1.0 \mathrm{~mm}$ for the strains S18 and S16, respectively, and only in the case the fermented juice samples.

Enterobacter cloacae strains E1005 and E1007 showed enlarged ZOI, $14 \pm 1.8$ and $13 \pm 1.5 \mathrm{~mm}$, respectively, compared to those of the unfermented juice samples $(13 \pm 1.1$ and $11 \pm 0.5 \mathrm{~mm}$ for the same strains).

In Table $\mathbf{2}$ and Figure $\mathbf{1}$ (isobolograms), the results of the combined activity of the two antibiotic agents and fermented and the unfermented cornelian cherry juice are presented.

As far as the Gram-positive strains are concerned, the greatest ZOI were recorded following the application of tigecycline in combination with fermented juice against E. faecium strains with a diameter of $65 \pm 4.8$ and $60 \pm 4.0 \mathrm{~mm}$ for the strains A1337 and A2020. The combination of vancomycin and fermented or unfermented juice exhibited similar ZOI, however, the fermented juice samples and vancomycin provided even larger zones compared to the unfermented juice.

In the case of E. faecalis, strains A1931 and A1957 displayed the greatest ZOI when treated with fermented cranberry juice in combination with tigecycline, i.e., $30 \pm 3.9$ and $38 \pm 2.1 \mathrm{~mm}$, respectively.
Staphylococcus aureus strains were the most resistant, even when tested with tigecycline and fermented cranberry juice. The strain S12 reached a diameter of $14 \pm 2.2 \mathrm{~mm}$ with the same combination. Vancomycin does not seem to have antimicrobial activity against these $S$. aureus strains.

Finally, E. cloacae strains provided significantly large ZOI in both cases, i.e., tigecycline and fermented juice or vancomycin and tigecycline. The former combination in strains E1000 and E1005 showed ZOI of diameters $50 \pm 4.1$ and $40 \pm 3.3 \mathrm{~mm}$, respectively.

\section{Determination of Antimicrobial Activity With MIC Method}

Minimum inhibitory concentration was defined as the lowest concentration of antibiotic (vancomycin, tigecycline), fermented and unfermented cranberry juice and their combination inhibiting visible growth of tested strains.

The lowest MIC values were recorded for tigecycline against S. aureus strains, varying from 0.004 to $0.032 \mu \mathrm{g} / \mathrm{mL}$, whereas in the case of vancomycin, MIC values ranged from 16 to $32 \mu \mathrm{g} / \mathrm{mL}$ for all the strains.

Fermented juice showed lower MIC values compared to the unfermented one, in the majority of the pathogens tested, reaching a value of $512 \mu \mathrm{g} / \mathrm{mL}$ in contrast to the unfermented 
TABLE 2 | Inhibition zones for $10 \mu \mathrm{L}$ unfermented and $10 \mu \mathrm{L}$ fermented cranberry juice $(1000 \mathrm{mg} / \mathrm{mL}+2 \% \mathrm{~L}$. paracasei) in combination with Vancomycin and Tigecycline (15 $\mathrm{\mu g} /$ disk) against Enterococcus faecium, E. faecalis, Enterobacter cloacae and S. aureus.

\begin{tabular}{|c|c|c|c|c|c|c|}
\hline Isolate & $\begin{array}{c}\text { Vancomycin + } \\
\text { Unfermented } \\
\text { cranberry juice } \\
\text { ZOI }\end{array}$ & $\begin{array}{c}\text { Vancomycin + } \\
\text { Fermented } \\
\text { cranberry juice } \\
\text { ZOI }\end{array}$ & $\begin{array}{c}\text { Tigecycline + } \\
\text { Unfermented } \\
\text { cranberry juice } \\
\text { ZOI }\end{array}$ & $\begin{array}{c}\text { Tigecycline + } \\
\text { Fermented } \\
\text { cranberry juice } \\
\text { ZOI }\end{array}$ & Vancomycin ZOI & Tigecycline ZOI \\
\hline & $(\mathrm{mm})$ & $(\mathrm{mm})$ & $(\mathrm{mm})$ & $(\mathrm{mm})$ & $(\mathrm{mm})$ & $(\mathrm{mm})$ \\
\hline \multicolumn{7}{|c|}{$\begin{array}{l}\text { Enterococcus } \\
\text { faecium }\end{array}$} \\
\hline A 1337 & $24 \pm 2.3^{a}$ & $28 \pm 2.2^{\mathrm{a}}$ & No zone & $65 \pm 4.8^{c}$ & $18 \pm 3$ & $42 \pm 7$ \\
\hline A 1658 & No zone & $23 \pm 2.6^{a}$ & $11 \pm 1.2^{b}$ & $29 \pm 2.8^{C}$ & $16 \pm 2.2$ & $25 \pm 4.3$ \\
\hline A 1668 & $15 \pm 1.5^{a}$ & $20 \pm 2.1^{a}$ & $28 \pm 2.2^{b}$ & $32 \pm 3.1^{b}$ & $15 \pm 2.5$ & $22 \pm 3.6$ \\
\hline A 2020 & $16 \pm 1.9^{a}$ & $19 \pm 1.5^{a}$ & $34 \pm 3.1^{b}$ & $60 \pm 4.0^{c}$ & $14 \pm 2.1$ & $45 \pm 4.8$ \\
\hline A 1709 & No zone & $24 \pm 2.4^{\mathrm{a}}$ & $12 \pm 1.8^{b}$ & $46 \pm 2.1^{c}$ & $12 \pm 1.1$ & $30 \pm 3.8$ \\
\hline \multicolumn{7}{|c|}{$\begin{array}{l}\text { Enterococcus } \\
\text { faecalis }\end{array}$} \\
\hline A 1931 & No zone & $19 \pm 2.0^{\mathrm{a}}$ & No zone & $30 \pm 3.9^{b}$ & $14 \pm 2.8$ & $14 \pm 2.2$ \\
\hline A 1957 & No zone & $24 \pm 2.5^{\mathrm{a}}$ & No zone & $38 \pm 2.1^{b}$ & $15 \pm 2.6$ & $35 \pm 3.5$ \\
\hline A 1940 & No zone & No zone & No zone & $15 \pm 1.2$ & $10 \pm 1.4$ & $10 \pm 1.2$ \\
\hline A 1951 & No zone & No zone & $10 \pm 0.5^{a}$ & $16 \pm 2.2^{b}$ & $8 \pm 0.8$ & $12 \pm 1.2$ \\
\hline A 1966 & $14 \pm 3.1^{a}$ & $20 \pm 3.1^{b}$ & $15 \pm 1.5^{\mathrm{a}}$ & $20 \pm 2.6^{b}$ & $11 \pm 1.2$ & $13 \pm 2.1$ \\
\hline \multicolumn{7}{|c|}{$\begin{array}{l}\text { Enterobacter } \\
\text { cloacae }\end{array}$} \\
\hline E 1000 & No zone & $25 \pm 1.4^{a}$ & $8 \pm 1.1^{b}$ & $50 \pm 4.1^{c}$ & - & $25 \pm 2.7$ \\
\hline E 1002 & $11 \pm 1.0^{\mathrm{a}}$ & $14 \pm 2.0^{b}$ & $28 \pm 3.3^{c}$ & $28 \pm 2.2^{C}$ & - & $20 \pm 1.8$ \\
\hline E 1004 & $10 \pm 1.1^{a}$ & $16 \pm 2.4^{b}$ & No zone & $30 \pm 2.6^{c}$ & - & $21 \pm 1.5$ \\
\hline E 1005 & No zone & $22 \pm 2.7^{a}$ & No zone & $40 \pm 3.3^{b}$ & - & $29 \pm 2.4$ \\
\hline E 1007 & $11 \pm 1.1^{a}$ & $17 \pm 2.0^{b}$ & No zone & $34 \pm 2.8^{c}$ & - & $30 \pm 3.4$ \\
\hline \multicolumn{7}{|c|}{ S. aureus } \\
\hline S 1530 & No zone & No zone & No zone & No zone & - & $10 \pm 1.1$ \\
\hline S 15 & No zone & No zone & No zone & $8 \pm 0.3$ & - & - \\
\hline S 12 & No zone & No zone & $10 \pm 1.8^{a}$ & $14 \pm 2.2^{b}$ & $12 \pm 2.3$ & $10 \pm 1.7$ \\
\hline S 18 & No zone & $8.2 \pm 2.3^{a}$ & $8 \pm 1.5^{a}$ & $11 \pm 1.6^{a}$ & $4 \pm 0.5$ & $4 \pm 0.4$ \\
\hline S 16 & No zone & $9.5 \pm 2.1^{\mathrm{a}}$ & $9 \pm 1.0^{\mathrm{a}}$ & $11 \pm 1.6^{b}$ & $5 \pm 0.8$ & $5 \pm 0.5$ \\
\hline
\end{tabular}

Different superscript letters in a row indicate statistically significant differences (ANOVA with Tukey's HSD post hoc comparisons).

cranberry juice, where MIC a value $1024 \mu \mathrm{g} / \mathrm{mL}$ appeared in most of the strains tested.

When the combination of antibiotics and juice was tested, MIC values were significantly lower. In particular, vancomycin and fermented juice reached MIC values ranging from $2 \mu \mathrm{g} / \mathrm{mL}$ (in strains A1658, E1007, S18) to $32 \mu \mathrm{g} / \mathrm{mL}$ (strain A1966). In comparison with MIC values from the combined activity of vancomycin and unfermented juice, the range was the same $(2-32 \mu \mathrm{g} / \mathrm{mL})$, but in each strain, the respective MIC values were higher with the fermented juice.

Minimum Inhibitory Concentration values with tigecycline were even lower, ranging from 0.002 to $0.064 \mu \mathrm{g} / \mathrm{mL}$ in combination with the fermented juice, and from 0.008 to $0.128 \mu \mathrm{g} / \mathrm{mL}$ in combination with the unfermented juice. $S$. aureus strains were the most sensitive strains followed by the E. cloacae strains.

In conclusion, tigecycline and fermented cornelian cherry juice was the most effective combination against the majority of pathogens tested.
At this point, it should be stated that the $\mathrm{pH}$ of the samples of the fermented and unfermented cranberry juice was adjusted to 3.5-3.6 to ensure that the results would not be confounded by their difference in acidity, and because a $\mathrm{pH}$ value of 3.6 is the optimum value for L. paracasei. This conclusion was reached in a previous study in our laboratory, in which the chemical composition of cranberry juice fermented with L. paracasei was determined at different $\mathrm{pH}$ values (Nouska et al., 2016). The total sugar concentration in the unfermented cranberry juice was $55 \mathrm{~g} / \mathrm{L}$ while the respective value in the fermented cranberry juice after $24 \mathrm{~h}$ of fermentation was $25.33 \mathrm{~g} / \mathrm{L}$.

\section{Determination of $\mathrm{FICl}$}

In Table 3, we observed that FICI $=0.5$, which reveals synergism, appeared in strain A2020 (E. faecium) when tigecycline and fermented cranberry juice is applied. Among E. cloacae strains, E1004, E1005, and E1007, exhibited FICI 0.5, 0.5, and 0.25, respectively, in the case of vancomycin.

Among S. aureus strains, only S18 had an FICI $=0.375$, and only in the case of vancomycin. In most of the 
Mantzourani et al.

Fermented Cornelean Cherry Juice and Antibiotics

A

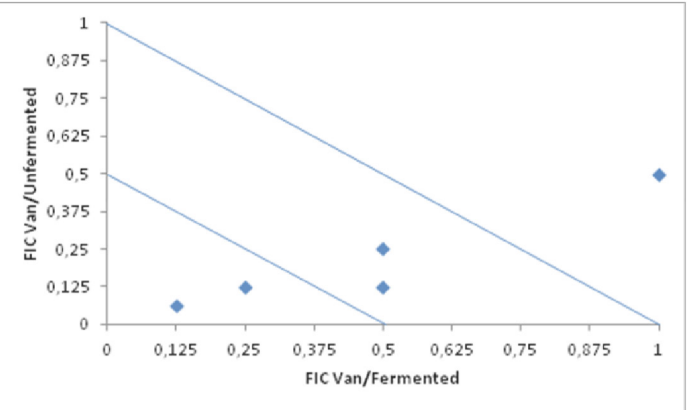

C

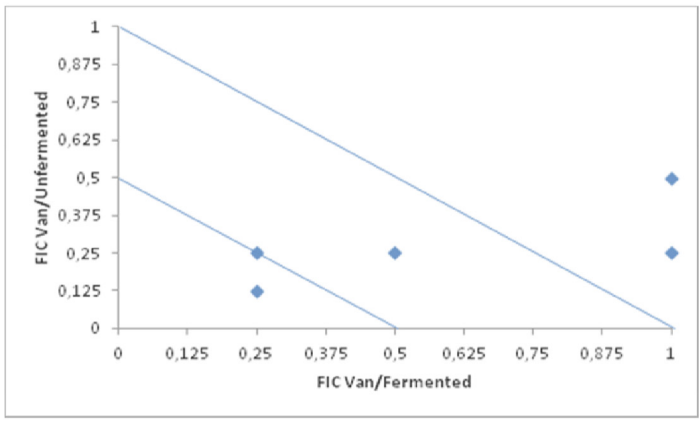

E

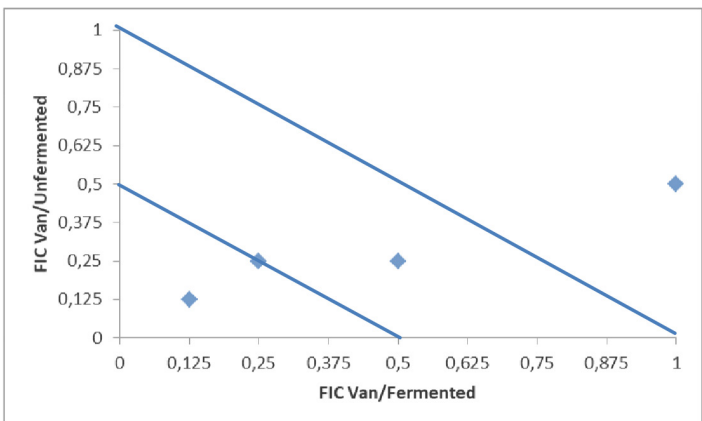

G

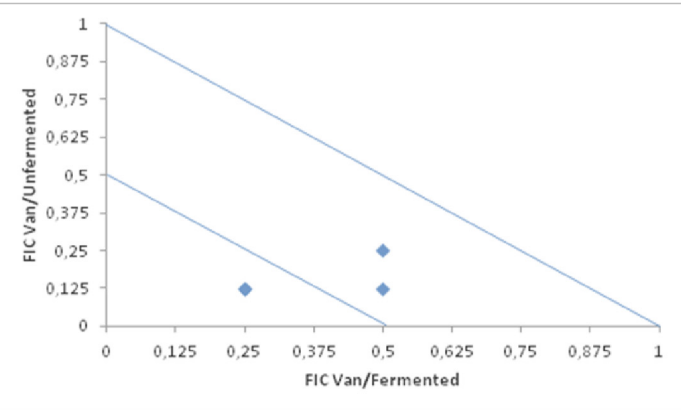

B

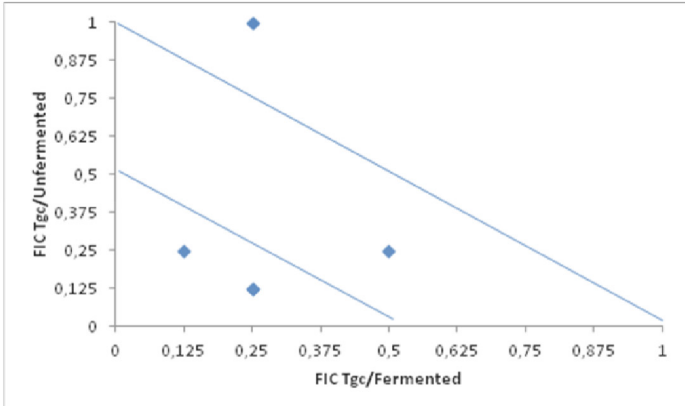

D

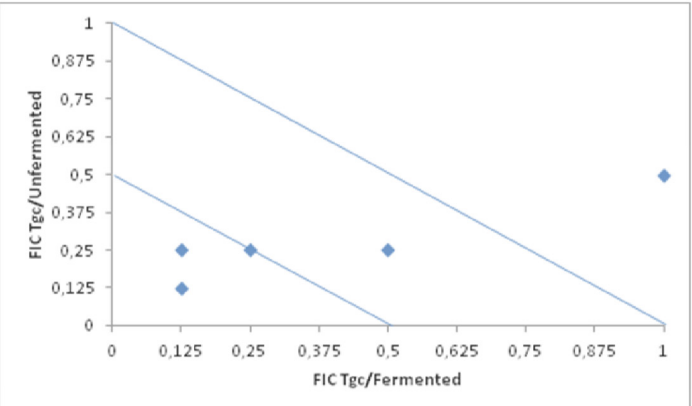

F

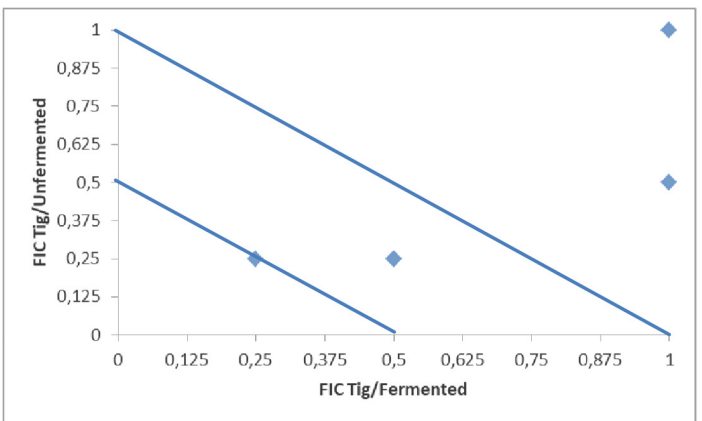

H

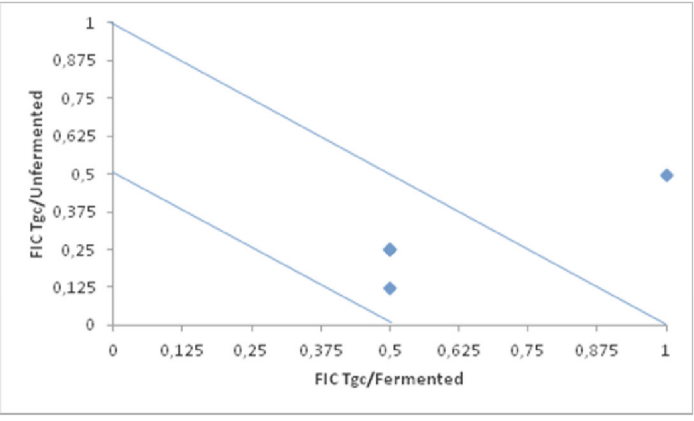

FIGURE 1 | Isobolograms of in vitro drugs and fermented and unfermented cranberry juice (vancomycin and tigecycline) against E. faecalis (A,B), E. faecium (C,D), E. cloacae $\mathbf{( E , F )}$ and $\mathbf{S}$. aureus $(\mathbf{G}, \mathbf{H})$.

Frontiers in Microbiology | www.frontiersin.org

6

June 2019 | Volume 10 | Article 1294 
TABLE 3 | MIC, FIC and FIC index (FICI) of fermented and unfermented cranberry juice with vancomycin and tigecycline by the microdilution method against pathogens.

\begin{tabular}{|c|c|c|c|c|c|c|c|c|c|c|c|c|c|c|}
\hline \multirow[b]{2}{*}{ Isolate } & \multicolumn{8}{|c|}{ Minimum Inhibitory Concentration $(\mu \mathrm{g} / \mathrm{mL})$} & \multicolumn{4}{|c|}{ Fractional Inhibitory Concentration } & \multicolumn{2}{|c|}{ FIC Index } \\
\hline & Van & Tig & $\begin{array}{l}\text { Unfermented } \\
\text { cranberry juice }\end{array}$ & $\begin{array}{c}\text { Fermented } \\
\text { cranberry juice }\end{array}$ & $\begin{array}{c}\text { Van }+ \\
\text { Unfermented } \\
\text { cranberry juice }\end{array}$ & $\begin{array}{c}\text { Van + Fermented } \\
\text { cranberry juice + } \\
\text { Van }\end{array}$ & $\begin{array}{c}\text { Tig + } \\
\text { Unfermented } \\
\text { cranberry juice }\end{array}$ & $\begin{array}{l}\text { Tig+ Fermented } \\
\text { cranberry juice }\end{array}$ & Van/Unt & Van/Fer & Tig/Unf & Tig/Fer & Van & Tig \\
\hline \multicolumn{15}{|c|}{$\begin{array}{l}\text { Enterococcus } \\
\text { faecium }\end{array}$} \\
\hline A 1337 & 32 & 0,128 & 1024 & 512 & 16 & 8 & 0,128 & 0,064 & 0,5 & 0,25 & 1 & 0,5 & 0,75 & 1,5 \\
\hline A 1658 & 16 & 0,064 & 512 & 512 & 8 & 2 & 0,032 & 0,016 & 0,5 & 0,125 & 0,5 & 0,25 & 0,625 & 0,75 \\
\hline A 1668 & 16 & 0,128 & 1024 & 512 & 16 & 8 & 0,128 & 0,032 & 1 & 0,5 & 1 & 0,25 & 1,5 & 1,25 \\
\hline A 2020 & 16 & 0,128 & 1024 & 1024 & 16 & 8 & 0,032 & 0,032 & 1 & 0,5 & 0,25 & 0,25 & 1,5 & 0,5 \\
\hline A 1709 & 32 & 0,128 & 512 & 512 & 32 & 8 & 0,128 & 0,032 & 1 & 0,25 & 1 & 0,25 & 1,25 & 1,25 \\
\hline \multicolumn{15}{|c|}{$\begin{array}{l}\text { Enterococcus } \\
\text { faecalis }\end{array}$} \\
\hline A 1931 & 32 & 0,128 & 1024 & 1024 & 16 & 8 & 0,128 & 0,032 & 0,5 & 0,25 & 1 & 0,25 & 0,75 & 1,25 \\
\hline A 1957 & 32 & 0,016 & 512 & 512 & 16 & 8 & 0,008 & 0,008 & 0,5 & 0,25 & 0,5 & 0,5 & 0,75 & 1 \\
\hline A 1940 & 16 & 0,128 & 1024 & 512 & 4 & 16 & 0,064 & 0,032 & 0,25 & 1 & 0,5 & 0,25 & 1,25 & 0,75 \\
\hline A 1951 & 16 & 0,128 & 512 & 512 & 16 & 8 & 0,128 & 0,016 & 1 & 0,5 & 1 & 0,125 & 1,5 & 1,125 \\
\hline A 1966 & 16 & 0,128 & 1024 & 1024 & 16 & 32 & 0,128 & 0,064 & 1 & 2 & 1 & 0,5 & 3 & 1,5 \\
\hline \multicolumn{15}{|c|}{$\begin{array}{l}\text { Enterobacter } \\
\text { cloacae }\end{array}$} \\
\hline E 1000 & 16 & 0,032 & 1024 & 1024 & 16 & 8 & 0,032 & 0,032 & 1 & 0,5 & 1 & 1 & 1,5 & 2 \\
\hline E 1002 & 16 & 0,064 & 1024 & 1024 & 8 & 4 & 0,032 & 0,016 & 0,5 & 0,25 & 0,5 & 0,25 & 0,75 & 0,75 \\
\hline E 1004 & 16 & 0,064 & 1024 & 1024 & 4 & 4 & 0,032 & 0,016 & 0,5 & 0,25 & 0,5 & 0,25 & 0,75 & 0,75 \\
\hline E 1005 & 16 & 0,008 & 1024 & 1024 & 4 & 4 & 0,002 & 0,002 & 0,5 & 0,25 & 0,25 & 0,25 & 0,75 & 0,5 \\
\hline E 1007 & 16 & 0,064 & 1024 & 1024 & 2 & 2 & 0,016 & 0,016 & 0,5 & 0,125 & 0,25 & 0,25 & 0,625 & 0,5 \\
\hline \multicolumn{15}{|c|}{ S. aureus } \\
\hline S 1530 & 16 & 0,032 & 512 & 1024 & 16 & 4 & 0,032 & 0,032 & 1 & 0,25 & 1 & 1 & 1,25 & 2 \\
\hline S 15 & 16 & 0,004 & 512 & 1024 & 8 & 4 & 0,004 & 0,002 & 0,5 & 0,25 & 1 & 0,5 & 0,75 & 1,5 \\
\hline S 12 & 16 & 0,016 & 512 & 1024 & 8 & 4 & 0,016 & 0,004 & 0,5 & 0,25 & 1 & 0,25 & 0,75 & 1,25 \\
\hline $\mathrm{S} 18$ & 16 & 0,016 & 512 & 1024 & 4 & 2 & 0,008 & 0,004 & 0,25 & 0,125 & 0,5 & 0,25 & 0,375 & 0,75 \\
\hline
\end{tabular}


strains examined, FICI revealed synergism or additivity. In few cases, we observed indifferent effect or even antagonism between antibiotic agents and cranberry juice. E. faecium included the greatest percentage of strains against which a synergistic interaction between juice and antibiotics was observed.

\section{DISCUSSION}

In this study, the antimicrobial activity of cornelian cherry juice, unfermented or fermented with the probiotic L. paracasei K5, was examined against Gram-positive bacteria ( . aureus - E. Faecium - E. faecalis) and Gram-negative bacteria (E. cloacae). In addition, the synergistic interaction of the fermented and unfermented juice and two antibiotic agents, vancomycin and tigecycline was determined.

The results support the hypothesis that phenolic compounds present in cranberry juice might contribute to an enhanced antimicrobial effect. Lacombe et al. (2012) reported that berries extracts could inhibit pathogens and help probiotic strains compete with them for the adhesion to the intestinal wall. In another study, the fermented cranberry juice was tested for its antimicrobial activity against Listeria monocytogenes, Vibrio parahaemolyticus, and E. coli O157:H7. The results implied that the increased levels of gallic acid after fermentation resulted in increased antibacterial activity (Vattem et al., 2004). In addition, when the interaction between the pathogens Mycobacterium tuberculosis and Penicillium avellaneum and Chinese herbal medicines was investigated, enhanced antibacterial activity of the fermented products of certain herbs was proved (Yu-Ling et al., 2013).

Phytochemicals, like tannins, and products which derive from their hydrolysis, like ellagic acid, are able to inhibit the growth of microorganisms. This inhibition takes place mostly by blocking the basic functions of the bacterial membrane (ion channels and proteolytic activity) (Muhammed et al., 2018). Proteins sensitive to $\mathrm{pH}$ and ionic strength may be inactivated from the phenolic induced acidity.

The mechanism that may explain the enlarged ZOI we observed when fermented cranberry juice was used against pathogens is the free radical quenching capacity that phenolic compounds have. More specifically, the ability of phenols to cause hyperacidification, alter the permeability of the transmembrane and protein ion-channels activating many signaling pathways to eukaryotes and prokaryotes. Studies have shown that methylated phenolic compounds have excellent antibacterial properties against Gram-positive bacteria (Osbourn, 1999).

The lower MIC values were recorded following the application of tigecycline and fermented juice, especially against $S$. aureus strains $(0,002-0,008 \mu \mathrm{g} / \mathrm{mL})$. The combination of vancomycin and fermented juice resulted in the lowest MIC values against $S$. aureus strains, as well. This synergistic effect is in accordance with cranberry synergies also recorded with other functional phytochemicals and fruit extracts.

Wojnicz et al. (2016), examined the impact of cranberry juice on the virulence factors and biofilm formation by E. faecalis strains isolated from urinary tract infections. Their results indicate that cranberry extract reduces survival of these strains, mostly because of the high level of polyphenols that generate hydrogen peroxide and alter the permeability of the cell membrane.

Microorganisms stressed by exposure to polyphenols upregulate defensive proteins and downregulate various metabolic proteins (Ferrazzano et al., 2011). This fact may explain the antagonism exhibited in E. faecalis strains between cranberry juice and antibiotics (Yamanaka-Okada et al., 2008).

Our results are moreover in accordance with a nosocomial study (Bonetta et al., 2017), where a total of 924 patients with prostate carcinoma were randomized to receive or not entericcoated cranberry extract for 6-7 weeks. Among the pathogens recorded were E. faecalis and E. cloacae strains. The outcome demonstrated that the treatment with enteric-coated cranberry extract could lessen the actinic damage to the bladder mucosa and reduce the inflammatory process, while the use of cranberry was shown to reduce the necessary antibiotic dose by $50 \%$, a clear indication of synergistic activity between cranberry and antibiotics.

Synergy can be defined as the ability of two or more functional components to mutually enhance their functionalities, so that when they are present together, their combined function rapidly improves the overall result of maintaining the homeostasis in eukaryotes or killing pathogenic bacteria. An example of this action is the co-administration of coffee with ellagic acid (Abraham, 1996) or even cranberry phenolics with $\mathrm{N}$-methyl-N-nitroso-guanidine (MNNG) that showed increased antimutagenic functionality (Vattem et al., 2004).

The mechanism of inhibition that phenolic compounds have against pathogens has more similarities with the action of vancomycin than that of tigecycline. Nevertheless, tigecycline combined with fermented cranberry juice displayed the most satisfying results against the pathogens tested.

Further investigation needs to be conducted in order to clarify the interaction between phenolic compounds from fruit extracts and antibiotics bioactive substances. A variety of functional foods, like beverages, could be produced and due to their synergistic or additive activity in combination with antibiotics, result in the application of such antibiotics in reduced doses against common pathogens.

\section{CONCLUSION}

Functional beverages may include probiotic strains and provide specific health benefits beyond those of any normal food source. In our study, fermented cornelian cherry juice was examined against Gram-positive and Gram-negative pathogenic bacteria alone or in combination with vancomycin or tigecycline. Results clearly indicated a synergistic or additive interaction between cranberry juice and the antibiotic agent in most cases. 
Further experiments should be conducted for the clarification of this interaction.

\section{DATA AVAILABILITY}

The raw data supporting the conclusions of this manuscript will be made available by the authors, without undue reservation, to any qualified researcher.

\section{REFERENCES}

Abraham, S. K. (1996). Anti -genotoxic effects in mice after the interaction between coffee and dietary constituents. Food Chem. Tocixol. 34, 15-20. doi: 10.1016/ 0278-6915(95)00085-2

Ahuja, S., Kaack, B., and Roberts, J. (1998). Loss of fimbrial adhesion with the addition of Vaccinum macrocarpon to the growth medium of P-fimbriated Escherichia coli. J. Urol. 159, 559-562. doi: 10.1016/s0022-5347(01)63983-1

Blumberg, J. B., Camesano, T. A., CassidyPenny, A., Manach, H. C., Ostertag, L. M., Sies, H., et al. (2013). Cranberries and their bioactive constituents in human health. Adv. Nutr. 4, 618-632. doi: 10.3945/an.113.004473

Bonetta, A., Roviello, G., Generali, D., Zanotti, L., Cappelletti, M. R., Pacifico, C., et al. (2017). Enteric-coated and highly standardized cranberry extract reduces antibiotic and nonsteroidal antiinflammatory drug use for urinary tract infections during radiotherapy for prostate carcinoma. Res. Rep. Urol. 9, 65-69. doi: 10.2147/RRU.S133538

Chondrou, P., Karapetsas, A., Kiousi, D. E., Tsela, D., Tiptiri-Kourpeti, A., Anestopoulos, I., et al. (2018). Lactobacillus paracasei K5 displays adhesion, antiproliferative activity and apoptotic effects in human colon cancer cells. Benef. Microbes. 9, 975-983. doi: 10.3920/BM2017.0183

EUCAST (2000). Terminology relating to methods for the determination of susceptibility of bacteria to antimicrobial agents. Clin. Microbiol. Infect. 6:503e508 e.

Ferrazzano, G. F., Amato, I., Ingenito, A., Zarrelli, A., Pinto, G., and Pollio, A. (2011). Plant polyphenols and their anticariogenic properties: a review. Molecules 16, 1486-1507. doi: 10.3390/molecules16021486

Fisher, K., and Phillips, C. (2009). The ecology, epidemiology and virulence of Enterococcus. Microbiology 155, 1749-1757. doi: 10.1099/mic.0.026385-0

Fratini, F., Mancini, S., Turchi, B., Friscia, E., Pistelli, L., Giusti, G., et al. (2017). A novel interpretation of the fractional inhibitory concentration index: the case origanum vulgare . and leptospermum scoparium from essential oils against Staphylococcus aureus strains. Microbiol. Res. 195, 11-17. doi: 10.1016/j.micres. 2016.11.005

Howell, A. B., Botto, H., Combescure, C., Blanc-Potard, A. B., Gausa, L., Matsumoto, T., et al. (2010). Dosage effect on uropathogenic Escherichia coli antiadhesion activity in urine following consumption of cranberry powder standardized for proanthocyanidin content: a multicentric randomized double blind study. BMC Infect. Dis. 10:94. doi: 10.1186/1471-2334-10-94

Howell, A. B., Vorsa, N., Der Marderosian, A., and Foo, L. Y. (1998). Inhibition of the adherence of P-fimbriated Escherichia coli to uroepithelial-cell surfaces by proanthocyanidin extracts from cranberries. N. Engl. J. Med. 339, 1085-1086. doi: 10.1056/NEJM199810083391516

Hur, S. J., Lee, S. Y., Kim, Y. C., Choi, I., and Kim, G. B. (2014). Effect of fermentation on the antioxidant activity in plant-based foods. Food Chem. 160, 346-356. doi: 10.1016/j.foodchem.2014.03.112

Jensen, H. D., Struve, C., Christensen, S. B., and Krogfelt, K. A. (2017). Cranberry juice and combinations of its organic acids are effective against experimental urinary tract infection. Front. Microbiol. 8:542. doi: 10.3389/fmicb.2017.00542

Kantachote, D., Charernjiratrakul, W., and Kamontam, U. (2008). Antibacterial activities of fermented plant beverages collected in Southern Thailand. Int. J. Biol. Sci. 8, 1280-1288. doi: 10.3923/jbs.2008.1280.1288

Kim, H. W., Chung, D. H., Kim, S. A., and Rhee, M. (2019). Synergistic cranberry juice combinations with natural-borne antimicrobials for the eradication of uropathogenic Escherichia coli biofilm within a short time. Lett. Appl. Microbiol. 68, 321-328. doi: 10.1111/lam.13140

\section{AUTHOR CONTRIBUTIONS}

IM and EB were responsible for the conception of the study. IM was also responsible for the writing of the manuscript. ES isolated and characterized the pathogenic bacteria. CB, SP, ET, and SK were responsible for the susceptibility testing. AA and GD performed statistic analysis. CT and CV were responsible for the determination of the FICI.

Kim, Y. W., Jeong, Y. J., Kim, A. Y., Son, H. H., Lee, J. A., Jung, C. H., et al. (2014). Lactobacillus brevis strains from fermented Aloe vera survive gastroduodenal environment and suppress common food borne enteropathogens. PLoS One 9:e90866. doi: 10.1371/journal.pone.0090866

Lacombe, A., Wu, V. C. H., White, J., Tadepalli, S., and Enroe, A. (2012). The antimicrobial properties of the lowbush blueberry (Vaccinium angustifolium) fractional components against foodborne pathogens and the conservation of probiotic Lactobacillus rhamnosus. Food Microbiol. 30, 124-131. doi: 10.1016/j. fm.2011.10.006

Lee, B. H., Lo, Y. H., and Pan, T. M. (2013). Antiobesity activity of Lactobacillus fermented soy milk products. J. Funct. Foods 5, 905-913. doi: 10.1016/j.jff.2013. 01.040

Liao, W. C., Wang, C. Y., Shyu, Y. T., Yu, R. C., and Ho, K. C. (2013). Influence of preprocessing methods and fermentation of adzuki beans on $\mathrm{g}$-aminobutyric acid (GABA) accumulation by lactic acid bacteria. J. Funct. Foods 5, 1108-1115. doi: 10.1016/j.jff.2013.03.006

Limon, R. I., Penas, E., Torino, M. I., Martinez-Villaluenga, C., Duenas, M., and Frias, J. (2015). Fermentation enhances the content of bioactive compounds in kidney bean extracts. Food Chem. 172, 343-352. doi: 10.1016/j.foodchem.2014. 09.084

Liu, C. F., Tung, Y. T., Wu, C. L., Lee, B. H., Hsu, W. H., and Pan, T. M. (2011). Antihypertensive effects of Lactobacillus-fermented milk orally administered to spontaneously hypertensive rats. J. Agric. Food Chem. 59, 4537-4543. doi: $10.1021 /$ jf104985v

Liu, Y., Black, M. A., Caron, L., and Camesano, T. A. (2006). Role of cranberry juice on molecular-scale surface characteristics and adhesion behavior of Escherichia coli. Biotechnol. Bioeng. 93, 297-305. doi: 10.1002/bit.20675

Mantzourani, I., Panopoulou, M., Theodoridou, I., Tsirogiannis, I., Papaemmanouil, V., Johnson, B., et al. (2015). Comparative antimicrobial susceptibility profiling of tigecycline and other antibiotics against clinical and environmental isolates. Int. J. Curr. Microbiol. App. Sci. 4, 384-396. doi: 10.1016/j.ijantimicag.2014.06.014

Muhammed, M., Kalyanam, N., Sivakumar, A., Sankaran, N., Shaheen, M., Anurag, P., et al. (2018). Cranberry seed fibre: a promising prebiotic fibre and its fermentation by the probiotic Bacillus coagulans MTCC 5856. Int. J. Food Sci. Technol. 53, 1640-1647. doi: 10.1111/ijfs.13747

Nouska, C., Kazakos, S., Mantzourani, I., Alexopoulos, A., Bezirtzoglou, E., and Plessas, S. (2016). Fermentation of cornus mas L. Juice for functional low alcoholic beverage production. Curr. Res. Nutr. Food Sci. 4, 119-124. doi: 10. 12944/CRNFSJ.4.Special-Issue-October.16

Osbourn, A. E. (1999). Antimicrobial phytoprotectans and fungal pathogens: a commentary. Fung.Genet. Biol. 26, 163-168. doi: 10.1006/fgbi.1999.1133

Othman, N. B., Roblain, D., Chammen, N., Thonart, P., and Hamdi, M. (2009). Antioxidant phenolic compounds loss during the fermentation of Chétoui olives. Food Chem. 116, 662-669. doi: 10.1016/j.foodchem.2009.02.084

Plessas, S., Galanis, A., Alexopoulos, A., Karapetsas, S., Chondrou, P., Fournomiti, M., et al. (2017). Isolation, characterization and evaluation of the probiotic potential of a novel Lactobacillus strain isolated from Feta-type cheese. Food Chem. 226, 102-108. doi: 10.1016/j.foodchem.2017. 01.052

Swain, M. R., Anandharaj, M., Ray, R. C., and Parveen Rani, R. (2014). Fermented fruits and vegetables of Asia: a potential source of probiotics. Biotechnol. Res. Int. 2014:19. doi: 10.1155/2014/250424

Todorov, S. D., Botes, M., Guigas, C., Schillinger, U., Wiid, I., Wachsman, M. B., et al. (2008). Boza, a natural source of probiotic lactic acid 
bacteria. J. Appl. Microbiol. 104, 465-477. doi: 10.1111/j.1365-2672.2007.0 3558

Torino, M. I., Limón, R. I., Martínez-Villaluenga, C., Makinen, S., Pihlanto, A., Vidal-Valverde, C., et al. (2013). Antioxidant and antihypertensive properties of liquid and solid state fermented lentils. Food Chem. 136, 1030-1037. doi: 10.1016/j.foodchem.2012.09.015

Vasconcelos, N. G., Croda, J., and Simionatto, S. (2018). Antibacterial mechanisms of cinnamon and its constituents: a review. Microb. Pathog. 120, 198-203. doi: 10.1016/j.micpath.2018.04.036

Vattem, D. A., Ghaedian, R., and Shetty, K. (2005). Enhancing health benefits of berries through phenolic antioxidant enrichment: focus on cranberry. Asia. Pac. J. Clin. Nutr. 14, 120-130.

Vattem, D. A., Lin, Y.-T., Labbe, R. G., and Shetty, K. (2004). Antimicrobial activity against select food-borne pathogens by phenolic antioxidants enriched in cranberry pomace by solid-state bioprocessing using the food grade fungus Rhizopus oligosporus. Process Biochem. 39, 1939-1946. doi: 10.1016/j.procbio. 2003.09.032

Wojnicz, D., Tichaczek-Goska, D., Korzekwa, K., Kicia, M., and Hendrich, A. B. (2016). Study of the impact of cranberry extract on the virulence factors and biofilm formation by Enterococcus faecalis strains isolated from urinary tract infections. Int. J. Food Sci. Nutr. 67, 1005-1016. doi: 10.1080/096 37486.2016 .1211996
Yamanaka-Okada, A., Sato, E., Kouchi, T., Kimizuka, R., Kato, T., and Okuda, K. (2008). Inhibitory effect of cranberry polyphenol on cariogenic bacteria. Bull. Tokyo Dent. Coll. 49, 107-112. doi: 10.2209/tdcpublication. 49.107

Yu-Ling, W., Li-Pyng, Y., and Chin-Shuh, C. (2013). Effects of fermentation treatment on antioxidant and antimicrobial activities of four common Chinese herbal medicinal residues by Aspergillus oryzae. J. Food Drug Anal. 21, 219-226. doi: 10.1016/j.jfda.2013. 05.013

Conflict of Interest Statement: The authors declare that the research was conducted in the absence of any commercial or financial relationships that could be construed as a potential conflict of interest.

Copyright (C) 2019 Mantzourani, Bontsidis, Plessas, Alexopoulos, Theodoridou, Tsigalou, Voidarou, Douganiotis, Kazakos, Stavropoulou and Bezirtzoglou. This is an open-access article distributed under the terms of the Creative Commons Attribution License (CC BY). The use, distribution or reproduction in other forums is permitted, provided the original author(s) and the copyright owner(s) are credited and that the original publication in this journal is cited, in accordance with accepted academic practice. No use, distribution or reproduction is permitted which does not comply with these terms. 